\title{
Ageing, Drama and Creativity: translating research into practice
}

Jackie Reynolds, Miriam Bernard, Jill Rezzano and Michelle Rickett

\section{ABSTRACT}

'Ageing, Drama and Creativity' was a pilot six session inter-professional training course delivered collaboratively by Keele University and the New Vic Theatre, Newcastle-underLyme, as part of our Arts and Humanities Research Council (AHRC) funded 'Ages and Stages' follow-on project. The course brought together a critical gerontological approach with artsbased educational practices and was designed to develop practice capabilities and age awareness amongst a diverse group of professionals working in arts organisations, the voluntary sector, local government, health and social services, and housing. This article describes how the course was developed and how participants were selected; details its aims and objectives; provides an overview of the sessions and a flavour of some of the exercises that were used; and considers findings from the structured evaluation alongside written reflections from participants.

\section{Introduction}

Developing gerontological interest in the humanities and in the possibilities of later-life creativity and personal change has sometimes been perceived as a slow process (Katz and Campbell 2005). This can be linked to perceptions that view older people as maybe past being creative (Groombridge 2006). Where research has suggested a decline in creativity in later life, this has clearly led to questions as to what extent such ageist assumptions are selffulfilling (Kastenbaum 1992). However, whilst there remains a tendency for research agendas to be driven more by the problems of an ageing population, there is also increasing 
recognition of the potential for personal growth and development through creativity and arts participation in later life.

Recognition of this potential, from a UK research context, was given a much-needed boost through the New Dynamics of Ageing (NDA) Programme: the largest research programme on ageing ever mounted in the UK (Walker, 2014). Funded by five UK Research Councils, the last phase of this nine year (2005-14) multidisciplinary research initiative introduced a new focus on arts and ageing by UK social gerontologists. It funded projects addressing a range of different art forms and types of participation, including studies relating to identity and the visual arts (Newman and Goulding 2013); the impact of participation in music-making (Hallam et al., 2011), and the role of arts and cultural activities in connecting older people in rural communities (Hennessy et al., 2013). The NDA also funded 'Ages and Stages: the place of theatre in representations and recollections of ageing'. This project (2009-12) involved collaboration between Keele University and the New Vic Theatre, Newcastle-under-Lyme, Staffordshire and was the impetus for the work we report on here.

Combining literary, cultural and archival analyses with qualitative interview work and research-led practice, the 'Ages and Stages' project undertaken by Bernard and colleagues (2015), provided both theoretical and practical understandings of the role that theatre plays in the lives of older people and in the wider community. The research was drawn together to create a new hour-long documentary drama 'Our Age, Our Stage' and the associated 'Ages and Stages Exhibition'. At its conclusion, the project also received 12 months' 'follow-on' funding from the UK's Arts and Humanities Research Council. The follow-on project, 'translating research into practice', involved: establishing the 'Ages and Stages Theatre Company'; devising and touring a new performance piece; and scoping out 
the potential for a Creative Age Festival in North Staffordshire. It also included the development, delivery and evaluation of the pilot training course we focus on in this article and which we titled 'Ageing, Drama and Creativity'. The course intentionally brought together arts practitioners with professionals from health, social care and housing backgrounds, and from the statutory, voluntary and private sectors. Below, we outline the origins and rationale for the course; describe the course content and how we incorporated theatre and drama into the sessions; and finally, from the evaluation findings, consider the implications for further educational work in this arena. We begin though with a brief review of some of the relevant literature and research in order to provide a context for what we have done.

\section{A Growing Evidence Base?}

'Ages and Stages' as a whole, and the training course specifically, needs to be viewed in the context of the limited existing literature focussed on theatre and drama participation by older people and the ways in which it may be developed as a medium for the inclusion of older adults and young people. In 2014, two of the authors of this current article undertook a critical review for the Arts and Humanities Research Council's 'Cultural Value Project' (Rickett and Bernard, 2014). Whilst the review drew on three earlier examinations of the impact of participatory arts on older people (Castora-Binkley, Noelker, Prohaska and Satariano, 2010; Mental Health Foundation, 2011; Noice, Noice and Kramer, 2013), it focused specifically on the cultural value that older people derive from their involvement in theatre and drama. The review included 77 documents consisting of published and unpublished research studies, evaluation reports, and descriptive overviews published as short pieces in journals, newspapers and magazines. 
The review highlights, in particular, the benefits and value of older people's theatre and drama participation on health and well-being; group relationships; and learning and creativity. In addition, a significant proportion of the literature focuses on the role of drama in enhancing or transforming group relationships, including through bringing generations together. One such educational example is a study by Hafford-Letchfield, Couchman, Webster and Avery (2010), which discusses the process and evaluation of a UK intergenerational drama project exploring older people's sexuality. The project brought together social work degree students, an older people's theatre group and three independent film makers and producers, to explore intimacy and sexuality in later life. The study not only challenged age-related stereotypes, but also highlighted the potential of artsbased research in informing practice, since it resulted in digital learning materials to be used in social work programmes.

Other examples of educational activities exploring the use of drama in the context of older people's health and well-being include a study by Eaton (2015) who evaluated the feasibility of using ethnodrama - involving nursing students and residents in an assisted living facility as an intervention to highlight late-life potential. There are also various examples of dramabased approaches within the training of dementia practitioners. Kontos, Mitchell, Mistry and Ballon (2010) report on a 12 week drama-based educational intervention aimed at improving person-centred care. They assessed the effectiveness of the drama-based component of the intervention using qualitative methods, and identified a range of positive outcomes. A similar focus and objectives can be found in the work of Anne Davis Basting, who specialises in creative engagement with people with memory loss. In 1996, Basting founded 'TimeSlips', an approach to creative storytelling, including staging plays that are 
inspired by people's stories (see Basting 2003). Over the last decade, an extensive educational programme has been developed to support the introduction of the 'TimeSlips' programme in a wide range of settings (TimeSlips n.d.).

Other existing research echoes much of the early interest and evidence about the benefits of (intergenerational) arts participation more broadly, especially in terms of health and wellbeing. Pioneering work into health benefits was led by Gene Cohen, a US-based psychiatrist, who published extensively on the subject of creativity and ageing before his death in 2009 . His research was concerned with understanding the physiological and psychological effects of arts participation on older people, and it was his work which importantly drew attention to the potential (as opposed to the problem) of ageing in relation to creativity (Cohen 2006), thus challenging a deficit model of later life.

In the UK, this orientation has been increasingly picked up by both practitioners and funders of arts programmes. Alongside the national NDA research programme, the Baring Foundation has been highly influential: launching a new funding programme in 2009 to support arts organisations working in participative ways with older people. This programme was initially informed by a report by David Cutler (2009), involving analysis of 120 case studies, which highlighted the value of arts participation for older people in relation to two inter-related dimensions of health (mental and physical), and to improved personal and community relations. However, the report concludes that despite the evident benefits, older people's arts participation tends to be overlooked in policy and service provision. In further developing their focus on arts and ageing, the Baring Foundation also commissioned the Mental Health Foundation (MHF)(in 2011) to undertake an 'Evidence Review of the Impact of Participatory Arts on Older People'. The review included 31 studies 
and 2040 participants, and offers further evidence to suggest 'that engaging with participatory art can improve the wellbeing of older people and mediate against the negative effects of becoming older' (MHF 2011:4). Positive impacts in terms of mental and physical wellbeing were identified at individual, community and societal levels (see also Cutler, Kelly and Silver 2011).

Alongside these kinds of findings, there is also growing evidence of the benefits of intergenerational working- in cultural arenas as well as in welfare settings. Some of the benefits have been identified as 'increased understanding, friendship, enjoyment and confidence', while outcomes specifically for older people have again been 'related to health and wellbeing, reduced isolation and a renewed sense of worth' (Springate, Atkinson and Martin 2008: v).

Overall, the findings of existing literature, including the New Dynamics of Ageing programme, broadly resonate with those of our own 'Ages and Stages' projects (Bernard et al., 2015), and have underpinned our curriculum development activities. These findings include:

- The importance of challenging stereotypes that creativity declines/ceases in old age.

- The significance of excitement, challenge and broadening horizons in terms of older people's theatre involvement.

- Connections between identity, belonging, well-being and self-confidence and how they can be enhanced through theatre/drama.

- The importance of participation, volunteering and taking part in creative activities, particularly at times of transition in later life. 
- The potential of theatre/drama as a medium for the inclusion of older and younger people, for positive health outcomes, and community cohesion.

Alongside considering the implications of such findings and how to translate them into a training course, we also reviewed existing training opportunities in order to avoid duplicating current provision and to address unmet need. In addition, we sought to build upon our own extensive experiences (and those of colleagues) in delivering gerontological and drama-based training.

\section{Existing Training Opportunities: Identifying Gaps and Building on Experience}

It is pertinent to note that, in the UK, existing intergenerational training programmes are often aimed at arts practitioners. London-based Magic Me, for example, is the UK's leading provider of intergenerational arts projects, and offers bespoke training for practitioners (Magic Me 2015). The Beth Johnson Foundation, a national charity sited in Stoke-on-Trent, hosts the Centre for Intergenerational Practice (Beth Johnson Foundation n.d.). It too provides training for a wide range of organisations but, although it provides toolkits, guides and other resources, these are focussed mainly on the practicalities, funding and structural aspects of intergenerational practice rather than on the use of creative arts-based approaches. In addition, a number of Higher Education Institutions in the UK and elsewhere have long offered a wide range of courses for those with an interest in gerontology. The Association for Gerontology in Higher Education produces an Online Directory of Educational Programmes in Gerontology and Geriatrics (AGHE 2015), which is a valuable source of information, especially for those studying in the US. However, very few - if any courses have a major focus on, or contributions from, the arts and humanities in general, or 
theatre and drama in particular, although they may address topics such as intergenerational relationships and late life creativity.

Some members of our research team have run academic programmes in Gerontology for over 20 years (see for example, Bernard, 1995; Bernard, Bornat and Johnson 1999) and we have all been involved in the training of practitioners and professionals including social workers, teachers, psychologists, doctors, nurses and arts practitioners. We were therefore able to draw on these varied experiences, and on the work of other Keele University colleagues who, in recent years, have developed and delivered interdisciplinary short courses on ageing, and on dementia, for practitioners in statutory and voluntary sector organisations (Ray and Chandler 2012; Revell and Stockwell 2013).

With backgrounds in drama, education and social gerontology, the research team perceived a strong rationale for a training course that addressed gaps in existing provision and would bring together participants from different employment sectors and backgrounds to share expertise and experiences in relation to ageing and intergenerational drama. Our own experiences and research had revealed the distinct lack of what might be termed a 'critical gerontological sensibility' in much training-related and educational activity: rarely are arts practitioners and care professionals brought together in creative ways unless it has to do with addressing identified problems such as truancy or family breakdown. By contrast, the pilot 'Ageing, Drama and Creativity' course originated in a non-problem-based and critical perspective, and was aimed at those who wished to learn both about the experience of ageing and how to use creative drama-based intergenerational interventions.

The non-accredited nature of the course meant that formal entry requirements were not necessary, and the fact that there was also no cost meant that we could aim to be as 
inclusive as possible. The pilot course was therefore intentionally wide-ranging, aiming to offer insights and opportunities for reflection on critical gerontological perspectives, as well as practical tools and techniques for developing drama-based intergenerational practices.

\section{Methods}

\section{The Training Course}

The course took place at the New Vic Theatre, Newcastle-under-Lyme, between February and April 2013. It comprised six three-hour participatory workshops (see Table 1 ) which, as noted earlier, drew on the research we had done on the 'Ages and Stages' project; on the various gerontology (Bernard) and drama (Rezzano) courses and training we had devised and taught for many years, and on the Ageing Studies Certificate being run by a Keele colleague for local authority staff. The workshops were facilitated by Dr Jill Rezzano (Head of Education), with support from Dr Miriam Bernard (Prof of Social Gerontology at Keele University). Formative evaluation of the course was undertaken by Dr Michelle Rickett (Research Associate on 'Ages and Stages') who took contemporaneous ethnographic notes of what happened in each session and by Dr Jackie Reynolds, who ran a formal summative evaluation session at the very end. The evaluation of the course received ethical approval by the University Ethical Review Panel at Keele University in September 2012.

\section{Course Participants}

Our intention was to pilot the course with 12 participants but we received an unexpectedly high volume of applications and eventually awarded places to 18 of the 59 applicants. In selecting participants, the main priorities were to bring together professionals from diverse 
settings, and to select people who had specifically indicated how they might use the training within their own practice.

The 18 participants were drawn from: arts organisations, the voluntary sector, local government, health and social services, and housing. Freelancers and volunteers were included as well as paid professionals from organisations. The group included a wide range of ages (from 20-72) and career levels. Three were males and the rest female. They came from across a wide geographical area, including Stoke-on-Trent, Newcastle-under-Lyme, Staffordshire Moorlands, Manchester, Chester, Poynton, Wolverhampton and Herefordshire. Though a number of the participants were experienced in working with young people, older people, or drama, they were all inexperienced in using intergenerational drama within their practice.

\section{Curriculum Design and Development}

As outlined in our literature review, the 'Ageing, Drama and Creativity' course was informed by existing literature and, in particular, by the findings of the 'Ages and Stages' research project. Those key findings, along with the gaps in existing provision that we identified were translated into the following overall aims of the course:

- To bring together professionals from a range of settings to learn and share expertise and experiences in relation to intergenerational drama.

- To increase the practice capabilities of learners by providing them with tools and techniques from drama, education and social gerontology.

- To increase the age awareness of learners through practical exercises, discussion and reflection on their own experiences and professional settings. 
- To create a network of learners who would be able to continue to support each other and share their experiences after the training ends.

The variation of experience in participatory drama held by the group members necessitated an approach rooted in 'active storytelling', common to theatre, and engaging members of the community in sharing and exploring experience (see also Schweitzer 2007). This technique allowed for an accessible route to fulfilling our learning objectives and examining the key concepts and themes of the workshops. Verbatim quotes from the original 'Ages and Stages' research interviews were used in a number of sessions both as catalysts to making theatre, and also to prompt conversations examining the underlying assumptions behind the language we use about ageing and older people. Our approach was also informed by the work of the Graeae Theatre Company (Graeae, n.d.) who challenge the preconceptions and prejudices surrounding people (particularly artists) with disabilities, and who explore body image, similarity and difference, as aids to understanding. This work also resonates with Michael Mangan's (2013) recent exploration of the ways in which theatre represents ageing and intergenerational relationships. Together, these approaches, with their examination and awareness of prevalent beliefs and the possibility of change, form the basis of much of our course and pedagogy.

Such approaches also require participants/learners to develop interactive physical and spoken responses, as opposed to being a passive audience. This was further built upon in the course through our use of Forum Theatre. Rooted in the practices of Brazilian Theatre Director, Augusto Boal, Forum Theatre draws on the pedagogies theorised in his (1979) work 'Theatre of the Oppressed'. Participants are asked to show and dramatise incidents of oppression or prejudice from their life and to then invite interventions from other 
participants. These, in turn, are enacted in the drama, with the suggested remedies to the oppressive situation being a way of envisaging change. The objective is the empowerment of the oppressed individual through a community of support, which in turn strengthens community bonds and cohesion.

The course and its curriculum were thus underpinned by a combination of research, drama theory and practice. The six workshops addressed key themes including: ageing, drama and creativity; stereotyping; intergenerational relationships; and intergenerational drama in practice, each addressing a number of the following learning objectives:

1) To introduce participants to thinking critically about ageing and about how we socially construct older - and younger - people.

2) To explore how an understanding of the life course can inform experiences of ageing and intergenerational relations.

3) To explore some key principles underpinning thinking about ageing and the relations between the generations.

4) To examine myths and assumptions about ageing; old people and young people.

5) To examine the value of chronological age as a basis for understanding ageing.

6) To look at the meaning of ageism and examples of ageism.

7) To look at how ageism manifests itself in, for example, our workplaces and at how it can be challenged.

8) To look at how we can use this material and these experiences in creative ways to help challenge ageism and inform other people's understandings of what ageing is like - for both older and younger people. 
9) To provide opportunities for participants to draw on - and reflect upon - their own experiences in the workshop debates and discussions.

Participants were provided with a variety of both academic and other resources in the form of articles, web links to podcasts and videos, and to organisations of interest. Three sessions involved invited speakers/performers, including members of the 'Ages and Stages Theatre Company', based at the New Vic. Half way through the course, participants also attended a performance by the Company, entitled 'Happy Returns', at one of a number of regional venues (including care homes). Although there were no formal assessments associated with the course, everyone wrote a reflective piece about 'Happy Returns', relating it to what they had learnt in the various sessions. In Table 1, we provide the outline of the course, identify learning objectives and resources for each session, and identify our relevant evaluation strategies across the course.

[Table 1 about here]

\section{Evaluation Design}

The research team adopted a qualitative strategy to the evaluation of the course, including the following methods and approaches:

- Contemporaneous ethnographic notes were taken by the Research Associate at each session.

- Participants were asked to write a reflective piece about their attendance at a 'Happy Returns' performance. 11 participants submitted their writing.

- A 45-minute evaluation session, led by Dr Jackie Reynolds and Dr Jill Rezzano, was included on the last day of the course. This incorporated a participatory tool (Body, 
Hearts and Minds tool; Buhaenko and Butler 2004), which involves participants attaching post-it notes with written comments onto a large outline of a body, carrying a basket and standing beside a bin: comments about things that they have learnt or found interesting are placed on the head; things that they have enjoyed are placed on the heart; things that they have found useful for their practice and plan to take away from the course are put in the basket; and comments about aspects of the course that have not been useful, or they have not liked are put in the bin. The evaluation session also included a recorded semi-structured discussion about participants' expectations and experiences, what worked well/less well, and how they would use the learning within their own settings. 10 participants took part in this session.

- Follow-up emails were sent out following the evaluation session, with the aim of including the views of those who were absent on that day, and also to capture any further reflections from those who had attended the session. Four email responses were received, three of which were from participants who had attended the final session.

Thematic analysis (by hand) of the reflective writings, responses to the participatory tool, semi-structured discussion and email responses was undertaken initially by Dr Reynolds. Other members of the research team looked at the data independently, and themes were then cross-checked in team discussions. Whilst there was general agreement regarding the themes, these discussions helped to refine the analysis. The ethnographic notes were used to create a detailed descriptive account of participant responses to the sessions; they have 
not been thematically analysed but rather used to provide a narrative of particular aspects of the course.

We now turn out attention to the key evaluation findings, before concluding with our thoughts about the implications of our experiences for others and for our future practice.

\section{Evaluation Findings}

We present our evaluation findings in three sections, each of which is informed by particular analytic methods used. We begin by focusing on the 'Happy Returns' performances, drawing upon the reflective journals that were submitted by course participants. We then focus on the practical exercises that students undertook in the final session of the course, by presenting evidence from the contemporaneous ethnographic notes made during this session. Finally, we present the findings of the final participatory evaluation session, following thematic analysis of the data that we collected.

\section{Happy Returns Performances}

'Happy Returns' is an interactive forum theatre piece, exploring intergenerational relationships, and set at a birthday party for three friends of different ages. The audience is included in a range of activities designed to generate reflection and discussion on issues of ageing and intergenerational relationships.

One example of the ways in which the audience is engaged in the action is a scene focusing on an older character's fear when passing a small group of teenagers on the street at night. The fears and assumptions of both the older character and the group of young people are voiced by the actors. They did not actually communicate directly with each other. The actors 
then ask audience members for their response to the scene and how they might have responded in a similar situation.

Course participants all attended a performance of 'Happy Returns' and 11 of them submitted a reflective journal entry about the experience. Their reflective pieces focus on various themes, including the quality of the acting; the issues that the play addresses; and observations of audience engagement. The most significant aspects of the feedback in terms of this article are the ways in which attending the performance supported the learning outcomes of the course and impacted on participants. For one participant, the performance had made her question stereotypes about ageing, and encouraged her to return to studying the issues associated with this:

The piece made me reflect on how much my own preferences and attitudes have changed with time, as well as making me question some of my own perceptions of age stereotypes. I think I may even return to some of the books about ageing that I studied during my university days in order to ponder the questions that it raised further!

For another participant, the key thing was the opportunity to see the principles taught on the course applied in practice, which gave her ideas for how to do the same in her own practice:

As the party got underway, I recognised elements of what we had covered in the workshops and the theory then had more reality as I connected it to the actual practice... I will be considering these elements and how I can integrate them into my 
practice. I am considering a staff workshop so that I can pass on some of the exercises and they can then facilitate workshops with our customers.

Several other participants identified ways in which they could apply their learning in specific contexts, including a theatre education professional who learnt new approaches to developing drama projects with intergenerational groups:

Overall, I was surprised by the piece as it was totally different to what I had expected. I think I was expecting a more traditional narrative approach as I would see in my own theatre venue. It has helped me to "think outside the box" in terms of forward planning for any future intergenerational drama projects.

Even for those with no background in theatre, the performance was seen as a valuable illustration of the potential of drama in the context of intergenerational practice:

I think the performance is a useful addition to the New Vic Ageing, Drama \& Creativity course content, showing what kind of projects can be mounted and how issues of age and ageing can be explored, other than through academic research. It is a useful and important introduction for anyone who has never been involved in any form of issue-based arts development work.

Various comments, including the quote above, highlight the value of integrating the performance as part of the 'Ageing, Drama and Creativity' course.

\section{$\underline{\text { Practical Exercises }}$}

Ten participants took part in this final workshop, in which they were asked to demonstrate and apply their learning from the course by developing a ten minute exercise that could be 
used in their work setting. This could either be based on an exercise covered in the course, or an original exercise. They were put into pre-allocated groups, according to their work area: housing/outreach; arts; health and social care; and voluntary/cultural sector. The following account of the session is based on contemporaneous ethnographic notes. On the day, the participants worked in groups of two and three and each group approached the task in a variety of ways, including:

- An exercise focused on place, which used photographs as the main stimulus.

- An exercise that explored and challenged generational perceptions and stereotypes, using photographs initially and, later, toys and literature.

- An exercise focused on holidays and sensory memories, using postcards as the initial stimulus.

- An exercise using drama that explored stereotypical assumptions between people of different generations.

Our use of visual provocations throughout the course reflected a classically theatrical approach to devising work and this was clearly influential in the exercises designed and delivered by participants. Three out of the four groups used graphic stimuli, including photographs and post cards. The fourth used a dramatic scene between an older and younger person to focus on assumptions and stereotypes and used changing audience perspectives to reveal the actuality of the encounter.

As a non-accredited, pilot training course, formal grading was not used, but rather verbal feedback from the workshop leader. The main strengths of the activities included the choices of resources that were used effectively by participants to challenge stereotypes though developing visual narratives. This involved clearly evidenced collaboration between 
participants. There were some suggestions for improvement, such as attention to pace and ideas for follow up activities, though these may have been addressed given more preparation and delivery time. As well as participants demonstrating their own learning, part of the value of the exercise lay in the opportunity to observe the approaches of others, and to give feedback, thus developing their critical skills.

\section{Final Evaluation Session}

The summative evaluation of the 'Ageing, Drama and Creativity' course, together with email responses, reveals a range of positive outcomes for participants which we have grouped into the following themes: style of learning; understanding ageism; impact on practice; networks, and suggestions for the future.

\section{Style of Learning}

Participants provided various insights into what worked well and there were numerous positive comments about the mix of activities and the delivery style. For example:

There was a good mix of active participation and the delivery of information. It encouraged us to be reflective learners, examining both our own practice and our beliefs about ageing.

The new ideas that were generated were found by some participants to be refreshing and inspirational: 'I just found doing this course so refreshing... And it's lovely to have that kind of energy back into my own practice and what I do'. There were also several positive comments relating to people valuing the opportunity to see the 'Happy Returns' intergenerational theatre piece as part of the course. 
As noted earlier, in the final session of the course, participants worked in groups to develop and lead a short exercise that could be used with intergenerational groups. This was found to be a particularly valuable experience, both in terms of leading the session, and as a result of the opportunity to learn from others. This was highlighted in the group discussion when comments included: 'I loved facilitating the sessions at the end. Really allowed me to think of ways to put things into practice', and 'everyone's different take on final workshop exercises was fabulous and has given me loads of ideas'.

\section{Understanding Ageism}

Participants' age awareness appeared to improve through insights gained from the academic resources and inputs, and through reflecting on and sharing their own experiences. One participant commented that she had learnt more about ageism and that she now understood its prevalence; another noted that it 'was wonderful to reflect on my own experience of ageing'. Taking part in the course had led one participant to independently read more about ageing and different people's experiences of it. Another participant reflected on the personal and professional impact of her increased understanding of age-related issues:

The benefits are hard to quantify in a specific way but in general terms my awareness of what it is to age, the impact of prejudice towards the elderly, institutionalised ageism and the portrayal of stereotypes have all been highlighted and these are points which will definitely influence the work I do. On a personal level, I am far more aware of not making ageist assumptions or remarks; elderly people have become more visible to me in my day-to-day life and I make a conscious effort not to make assumptions based on age-related stereotypes. 


\section{Impact on Practice}

An active learning approach, through which participants took part in a wide range of practical icebreakers, exercises and games, gave people many ideas for activities that they could use in groups that they work with. Some reported increased confidence in facilitating activities, and some gave specific examples of how they had already adapted their own practice to include approaches/techniques learnt on the course. One participant commented that:

I will take away the practical ideas. I have never facilitated drama sessions before; however, I am currently co-ordinating an intergenerational quilting project and lots of these exercises would complement this project.

Another discussed the ways in which she had used many of the activities in her creative writing workshops with children, and how her overall approach to developing workshops had been influenced by her realisation of the links between different creative art forms: I've come to appreciate even more quite how closely arts activities relate to one another-art, drama, music and writing are all interlinked and impact upon each other in intriguing ways. This is something that's been a useful realisation and I have found that I'm incorporating music, movement, improvisation and art into my workshops much more than I previously had.

For a number of other participants, attending the course had prompted them to plan new intergenerational projects - for example: '[I] Will look at setting up intergenerational projects for dyslexic students and mums'. Furthermore, not all participants were experienced in working with older people and, for one person, the course had prompted her 
to reject the notion that she could only work with young people. There was some interest in further study, including a learner who was applying to study on a 'Developing Arts for Health' course, and there were also initial indications that some learning was being cascaded to work colleagues (though this would require a longer-term evaluation strategy to fully assess). We do also acknowledge the possibility that the course may have impacted more significantly on those participants who completed the evaluations than on those who did not. A longer term evaluation would be valuable both in fully assessing longer-term and unexpected outcomes, and also in identifying those for whom the course had limited impact on their practice.

\section{Networks}

A particular strength of the course was the diverse ages and backgrounds of participants, which provided a range of different experiences and perspectives, as well as establishing networks to help develop future projects. People valued the opportunity to network with other professionals interested in using intergenerational drama in a range of settings and to draw from each other's experiences, ideas and expertise. We know too that some participants have maintained contact with each other and indeed with us: some having become involved in subsequent local developments including the realisation of plans to hold an annual festival celebrating creativity in later life and showcasing the work of older people, arts organisations and practitioners (Live Age Festival, n.d.).

\section{Suggestions for the Future}

One participant felt that the experience of leading the final workshop activity had been such a boost to her confidence that it would have been good to have had similar opportunities earlier in the course perhaps by contributing to leading warm-up or ice-breaking activities. There were also a number of other comments about what could be done differently in the 
future. Participant numbers had fluctuated, partly due to adverse winter weather conditions, and because not everyone could attend every session. A small number of participants suggested that this made it more difficult for the group to get to know each other although some people did stay on to have lunch together after some sessions. Setting aside time for networking at each session might help address this on any future course.

Whilst the practical nature of the course seemed to be very successful, one participant expressed further interest in the theoretical basis of the work, and in related research. A future course could potentially include more academic content, depending on levels of interest. Similarly, a more wide-ranging and challenging reading list could help those participants who wish to engage more deeply with theory. Finally, given more time, it may have been valuable to include a short evaluation exercise at the end of each workshop, to capture people's more immediate reflections.

\section{Conclusions}

In conclusion, the level of interest generated by the 'Ageing, Drama and Creativity' course is an important finding in itself, demonstrating the potential demand for such arts-based interprofessional and interdisciplinary training. Moreover, the feedback from participants was overwhelmingly positive, with the approach to active learning; the opportunities for reflection on one's own attitudes and experiences of ageing; and the emphasis on gaining ideas and tools to be applied in people's practice; all being seen as particularly valuable aspects of the course.

The course was also a valuable opportunity to further develop the impact of the original 'Ages and Stages' project by using (some of) our research findings and practical drama/devising techniques to directly inform teaching and learning. We were thus able to 
draw together perspectives from critical gerontology with those from best practice in drama and theatre education, and to enrich them with original research data and findings. Our work thus builds upon the increasing interest in interdisciplinary collaborations, and artsbased research, and highlights ways in which innovative partnerships between academics and arts practitioners can result in programmes of training that deepen impact and engagement in both theory and practice. This approach sits comfortably, we would suggest, with developments over the last decade in what the American cultural commentator and literary critic Margaret Morganrothe Gullette $(2004,2008)$ terms 'age studies'. Age studies endeavours to understand age and ageing as complex, intersectional social and psychological constructions, and as a set of mediated relationships among people located at different phases of the life course. Moreover, we would concur strongly with Gullette (2015: 27) when she also argues that it 'should be something that the youngest can look forward to with anticipation'.

Finally, in research terms, it would be instructive to follow-up participants and, educationally, it would be encouraging if the pilot course could be adopted, at least in part, alongside other continuing professional development opportunities in our own institution or elsewhere. It is, however, pertinent to note that as our population continues to age, many Higher Education Institutions in the UK seem to be withdrawing from, rather than investing in, gerontological education. 
References

AGHE (2015) Online Directory of Educational Programmes in Gerontology and Geriatrics. Washington: Association for Gerontology in Higher Education. Retrieved from: http://www.aghedirectory.org/

Basting, A. (2003) Reading the story behind the story: context and content in stories by people with dementia. Generations, vol. 27 (3): 25-29.

Bernard, M. (1995) Teaching Gerontology: reflections from a British University. Education and Ageing, vol. 10(2): 90-102.

Bernard, M., Bornat, J. and Johnson, J. (1999) Social Gerontology Education: is there a future? Generations Review, vol. 9(3): 4-8.

Bernard, M., Rickett, M., Amigoni, D., Munro, L., Murray, M. \& Rezzano, J. (2015) Ages and Stages: the place of theatre in the lives of older people. Ageing and Society, vol. 35 (6): 1119-1145. Doi:10.1017/S0144686X14000038

Beth Johnson Foundation: A Future for all Ages. (n.d.) Retrieved 12 August, 2015, from Beth Johnson Foundation website, https://www.bjf.org.uk/

Boal, A. (1979) Theatre of the Oppressed. London, Pluto.

Buhaenko, H. Butler, V. (2004) What Men and Women Want: A practical guide to gender and participation. Oxford, Oxfam. Retrieved from: http://policy-

practice.oxfam.org.uk/publications/what-men-and-women-want-a-practical-guide-togender-and-participation-115407

Cohen, G. (2006) Research on Creativity and Aging: The Positive Impact of the Arts on Health and Illness. Generations, vol. 30 (1): 7-15 
Castora-Binkley, M., Noelker, LS., Prohaska, T. and Satariano, W. 2010. Impact of Arts Participation on Health Outcomes for Older Adults. Journal of Aging, Humanities, and the Arts, vol. 4 (4): 352-367.

Cutler, D. (2009) Ageing Artfully: Older People and Professional Participatory Arts in the UK. London: The Baring Foundation.

Cutler, D., Kelly, D. and Silver, S. (2011) Creative Homes: How the Arts can contribute to quality of life in residential care. London, The Baring Foundation. Retrieved from: http://www.baringfoundation.org.uk/CreativeCareHomes.pdf

Eaton, J. (2015) The Feasibility of Ethnodrama as Intervention to Highlight Late Life Potential for Nursing Students and Older Adults. Gerontology \& Geriatrics Education, vol. 36 (2): 204-222 doi: 10.1080/02701960.2015.1015122

Graeae Theatre Company (n.d.) Retrieved 25 November 2015, from Graeae website, http://www.graeae.org

Groombridge, B. (2006) Extra Time: Arts, Health and Learning in Later Life: Frank Glendenning Memorial Lecture 2006 (summary document). Leicester, Niace. Retrieved from: http://www.cpa.org.uk/aea/Frank Glendenning Memorial Lecture-2006.pdf

Gullette, M.M. (2004) Aged by Culture. Chicago: University of Chicago Press.

Gullette, M.M. (2008) What's Age Got to Do with It? My Life in Age Studies. Journal of Aging Studies, 22 (2): 189-95.

Gullette, M.M. (2015) 'Aged by culture' in J. Twigg and W. Martin (Eds) Routledge Handbook of Cultural Gerontology. Abingdon, Oxon: Routledge. 
Hafford-Letchfield, T., Couchman, W., Webster, M. \& Avery, P. (2010) A Drama Project about Older People's Intimacy and Sexuality. Educational Gerontology, vol. 36(7): 604621.

Hallam, S., Creech, A., Gaunt, H., Pincas, A., Varvarigou, M., and McQueen, H. (2011) Music for Life Project: The role of participation in community music activities in promoting social engagement and well-being in older people. (NDA Findings 9) Sheffield: NDA Research programme. Retrieved from: http://www.newdynamics.group.shef.ac.uk/nda-findings$\underline{9 . h t m l}$

Hennessy, C. et al., (2013) Grey and Pleasant Land? An interdisciplinary exploration of the connectivity of older people in rural civic society. (NDA Findings 30) Sheffield: NDA Research programme. Retrieved from: http://www.newdynamics.group.shef.ac.uk/ndafindings-30.html

Kastenbaum, R. (1992) 'The Creative Process: A Life-span Approach' in T.Cole, D.Van Tassel and R.Kastenbaum (Eds) Handbook of the Humanities and Aging. New York: Springer Publishing Company.

Katz, S., Campbell, E. (2005) 'Creativity Across the Life Course? Titian, Michelangelo, and Older Artist Narratives' in S. Katz Cultural Aging: Life Course, Lifestyle, and Senior Worlds. Ontario: Broadview Press.

Kontos, P.C., Mitchell, G.J., Mistry, B., and Ballon, B. (2010) Using drama to improve personcentred dementia care. International Journal of Older People Nursing, vol. 5 (2): 159-168

Live Age Festival (n.d.) Retrieved 27 November 2015, from Live Age Festival website, http://www.liveagefestival.co.uk 
Magic Me: Connecting Generations (n.d.) Retrieved 12 August, 2015, from Magic Me website, http://magicme.co.uk/

Mangan, M. (2013) Staging Ageing: Theatre, Performance and the Narrative of Decline. Bristol, Intellect.

Mental Health Foundation (2011) An Evidence Review of the Impact of Participatory Arts on Older People. Edinburgh: Mental Health Foundation.

Newman, A., Goulding, A. (2013) Contemporary visual art and identity construction - wellbeing among older people. (NDA Findings 26). Sheffield: NDA Research programme. Retrieved from: http://www.newdynamics.group.shef.ac.uk/nda-findings-26.html

Noice, T., Noice, H. and Kramer, A. 2013. Participatory Arts for Older Adults: A Review of Benefits and Challenges. The Gerontologist. Advance Access: December 2013. doi:10.1093/geront/gnt138

Ray, M., Chandler, S. (2012) Ageing Studies Certificate: Information for Local Authorities. Keele University: Unpublished report.

Revell, A., Stockwell, S. (2013) Ageing Studies Certificate: Evaluation Report. Keele University, Unpublished evaluation report.

Rickett, M., Bernard, M. (2014) Ageing, Drama and Creativity: A Critical Review. (Final report to AHRC). Newcastle-under-Lyme, Keele University.

Schweitzer, P. (2007) Reminiscence Theatre: Making Theatre from Memories. London, Jessica Kingsley. 
Springate, I., Atkinson, M., and Martin, K. (2008) Intergenerational Practice: a Review of the Literature. (LGA Research Report F/SR262). Slough: NFER.

TimeSlips: Creative Storytelling (n.d.) Retrieved 12 August, 2015, from TimeSlips website, http://www.timeslips.org/

Walker, A. (2014) 'Towards a new science of ageing', Chapter 1 (p1-23) in Walker, A. (ed) The New Science of Ageing, Bristol: Policy Press. 